Article

\title{
Enhanced High-Temperature Mechanical Properties of Al-Cu-Li Alloy through T1 Coarsening Inhibition and Ce-Containing Intermetallic Refinement
}

\author{
Xinxiang Yu ${ }^{1,2, * \mathbb{D}}$, Zhiguo Zhao ${ }^{3}$, Dandan Shi ${ }^{3}$, Han Dai ${ }^{1,2}$, Jie Sun ${ }^{1}$ and Xiaoyan Dong ${ }^{1}$ \\ 1 Laboratory of Advanced Light Alloy Materials and Devices, Yantai Nanshan University, Longkou 265713, \\ China; daihan1985@189.cn (H.D.); sunjie19860304@163.com (J.S.); pigeon929@126.com (X.D.) \\ 2 Postdoctoral Station of Nanshan Group Co., Ltd., Longkou 265706, China \\ 3 Testing Center, Hang Xin Material Technology Co., Ltd., Longkou 264006, China; \\ zhaozhiguo@nanshan.com.cn (Z.Z.); shidandan@nanshan.com.cn (D.S.) \\ * Correspondence: yuxinxiangcn@163.com; Tel.: +86-0535-859-0938
}

Received: 26 April 2019; Accepted: 5 May 2019; Published: 9 May 2019

\begin{abstract}
The effects of the addition of $0.29 \mathrm{wt} \% \mathrm{Ce}$ on the high-temperature mechanical properties of an $\mathrm{Al}-\mathrm{Cu}-\mathrm{Li}$ alloy were investigated. Ce addition contributes to $\mathrm{T} 1\left(\mathrm{Al}_{2} \mathrm{CuLi}\right)$ phase coarsening inhibition and Ce-containing intermetallic refinement which greatly improved the thermal stability and high-temperature deformation uniformity of this alloy. On the one hand, small Ce in solid solution and segregation at phase interface can effectively prevent the diffusion and convergence of the main element $\mathrm{Cu}$ on $\mathrm{T} 1$ phase during thermal exposure. Therefore, the thermal stability of Ce-containing alloy substantiality improves during thermal exposure at the medium-high-temperature stage $\left(170^{\circ} \mathrm{C}\right.$ to $270{ }^{\circ} \mathrm{C}$ ). On the other hand, the increment of the tensile elongation in Ce-containing alloy is much greater than that in Ce-free alloy at high temperatures tensile test, because the refined $\mathrm{Al}_{8} \mathrm{Cu}_{4} \mathrm{Ce}$ intermetallic phase with high-temperature stability are mainly located in the fracture area with plastic fracture characteristics. This work provides a new method for enhancing high-temperature mechanical properties of $\mathrm{Al}-\mathrm{Cu}-\mathrm{Li}$ alloy which could be used as a construction material for high-temperature structural components.
\end{abstract}

Keywords: Al-Cu-Li alloy; cerium; thermal stability; intermetallic; microstructure

\section{Introduction}

$\mathrm{Al}-\mathrm{Cu}-\mathrm{Li}$ alloy has a number of advantages over conventional aluminum alloy, such as lower density, higher strength, higher fracture toughness, better fatigue, and corrosion resistance [1,2]. These properties contribute to the improvement of payload and fuel efficiency, thereby having made $\mathrm{Al}-\mathrm{Cu}-\mathrm{Li}$ alloy a competitive alternative to conventional $2 x x x$ and $7 x x x$ series materials in new aircraft designs [3]. The evaluation of thermal stability of Al-Cu-Li alloy is urgently needed for the potential application on fuselages, wing structures, bulkheads near the engine, as well as other high-temperature structural components which require high-temperature resistance in modern fighter aircraft [4]. So far the lower exposure temperatures in the range of $343 \mathrm{~K}$ to $358 \mathrm{~K}\left(70{ }^{\circ} \mathrm{C}\right.$ to $\left.85^{\circ} \mathrm{C}\right)$ have been chosen to simulate the environment to which the wings and fuselage structures of commercial aircraft are exposed [5]. Reports have also been made on thermal exposure of $\mathrm{Al}-\mathrm{Cu}-\mathrm{Li}$ alloys at medium-high-temperatures (below $200{ }^{\circ} \mathrm{C}$ ) [6,7]. However, materials near the engine, like bulkheads, are usually exposed to high-temperature environments $\left(>200^{\circ} \mathrm{C}\right)$. Therefore, the changes of microstructure and performance of $\mathrm{Al}-\mathrm{Cu}-\mathrm{Li}$ alloy in this temperature range requires further clarification, yet it has seldom been reported.

The high-temperature $\left(>70^{\circ} \mathrm{C}\right)$ mechanical properties of $\mathrm{Al}-\mathrm{Cu}-\mathrm{Li}$ alloy depends on the thermal stability of its precipitates which includes $\mathrm{T} 1\left(\mathrm{Al}_{2} \mathrm{CuLi}\right), \delta^{\prime}\left(\mathrm{Al}_{3} \mathrm{Li}\right)$, and $\theta^{\prime}\left(\mathrm{Al}_{2} \mathrm{Cu}\right)[8]$. Among them, 
the $\mathrm{T} 1$ phase is the most stable [9], as the plates of $\mathrm{T} 1$ are very thin $(\sim 1.3 \mathrm{~nm})$ and their thickness is very stable with aging at temperatures below $\sim 170{ }^{\circ} \mathrm{C}$ [2]. Therefore, we chose $\mathrm{T} 1$ as the dominant strengthening phase in $\mathrm{Al}-\mathrm{Cu}-\mathrm{Li}$ alloy. The $\mathrm{T} 1$ phase can be promoted by increasing $\mathrm{Cu} / \mathrm{Li}$ ratio [10] and small pre-stretching prior to artificial aging $[2,11]$. In addition, the thermal stability of $\mathrm{T} 1$, a $\mathrm{Cu}$-containing precipitate, can be further improved by adding rare elements. A small addition of Sc [12], $\mathrm{Y}$ [13], La [14], and $\mathrm{Er}$ [15] can decrease the diffusion rate of the main alloying element $\mathrm{Cu}$, thereby delaying the coarsening of $\mathrm{Cu}$-containing precipitates in $\mathrm{Al}$ alloy. $\mathrm{Ce}$ as rare earth element also has the same function [16,17], so the coarsening process of the $\mathrm{Cu}$-containing precipitate in Ce-containing alloy at high temperature can be delayed [18] and the thermal stability of these alloys can be improved, e.g., the addition of Ce inhibits the coarsening of $\Omega\left(\mathrm{Al}_{2} \mathrm{Cu}\right)$ precipitate in $\mathrm{Al}-\mathrm{Cu}-\mathrm{Mg}-\mathrm{Ag}$ alloy [19] and T1 $\left(\mathrm{Al}_{2} \mathrm{CuLi}\right)$ precipitate in $\mathrm{Al}-\mathrm{Cu}-\mathrm{Li}$ alloy [20]. Ce can also contribute to the refinement of intermetallic of aluminum alloys, e.g., a refined eutectic structure in $7055 \mathrm{Al}$ alloy [21], $\mathrm{Al}-6.7 \mathrm{Zn}-2.6 \mathrm{Mg}-2.6 \mathrm{Cu}(\mathrm{wt} \%)$ alloy [22], and $\mathrm{Al}-\mathrm{Cu}-\mathrm{Li}$ alloy [23] have been reported. A large number of small $\mathrm{Al}_{8} \mathrm{Cu}_{4} \mathrm{Ce}$ phases were also formed in Ce-containing Al-Cu-Li alloy after homogenization in our previous work [24]. These high melting point intermetallics do not coarsen evidently at elevated temperatures [25], which might strengthen grain boundaries and serve as obstacles to slip and creep at high temperatures to improve high-temperature mechanical properties of Ce-containing $\mathrm{Al}-\mathrm{Cu}-\mathrm{Li}$ alloy. Refined Ce-containing intermetallic improves the high-temperature mechanical properties of the $\mathrm{Sn}-3.8 \mathrm{Ag}-0.7 \mathrm{Cu}$ solder joint [26], but research on the Al-Cu-Li alloy from this approach has seldom been made.

The purpose of this work is to investigate the effect of Ce addition on the inhibition of the main strength phase $\mathrm{T} 1$ coarsening during high-temperature exposure in high $\mathrm{Cu} / \mathrm{Li}$ ratio $\mathrm{Al}-\mathrm{Cu}-\mathrm{Li}$ alloy at $\mathrm{T} 8$ temper ( $6 \%$ pre-stretching), and the effect of $\mathrm{Ce}$ on the diffusion of $\mathrm{Cu}$ in this alloy by a designed diffusion couple. Moreover, the enhanced deformation uniformity and strength of the Al-Cu-Li alloy owing to the refined Ce-containing intermetallic during high-temperature tensile were also studied in this paper.

\section{Materials and Methods}

The materials used in this study were a $0.29 \mathrm{wt} \% \mathrm{Ce}$-containing alloy and a Ce-free $\mathrm{Al}-\mathrm{Cu}-\mathrm{Li}$ alloy, as shown in Table 1. Master alloys of Al-Cu (50 wt\%), Al-Zr (3.29 wt \%), Al-Ce (10 wt \%), and pure Ag, $\mathrm{Mg}$, $\mathrm{Li}$, and the remaining $\mathrm{Al}$ were melted in a vacuum induction melting furnace in a controlled Ar gas atmosphere, in a high-purity graphite crucible [1]. The casting was performed in $\mathrm{Ar}$, using a Cu mold surrounded by cooling water [27]. The ingots were homogenized through a two-step homogenization course at $470{ }^{\circ} \mathrm{C}, 8 \mathrm{~h}$ and $510{ }^{\circ} \mathrm{C}, 16 \mathrm{~h}$ in a salt bath, followed by air cooling. After that, the ingots were hot-rolled from $23 \mathrm{~mm}$ to $4.5 \mathrm{~mm}$ and finally cold-rolled to $2.2 \mathrm{~mm}$ in thickness. Subsequently, the plates were solution-treated at $520^{\circ} \mathrm{C}$ for $1 \mathrm{~h}$, water-quenched, and finally aged at $150{ }^{\circ} \mathrm{C}$ with pre-stretching at $6 \%$ (T8 temper).

Table 1. Chemical composition of investigated alloys ( $\mathrm{wt} \%$ ).

\begin{tabular}{ccccccc}
\hline Alloys & $\mathbf{L i}$ & $\mathbf{C u}$ & $\mathbf{A g}$ & $\mathbf{M g}$ & $\mathbf{Z r}$ & $\mathbf{C e}$ \\
\hline Ce-free alloy & 1.29 & 4.62 & 0.41 & 0.39 & 0.14 & - \\
Ce-containing alloy & 1.31 & 4.63 & 0.38 & 0.40 & 0.13 & 0.29 \\
\hline
\end{tabular}

In order to assess the thermal stability of the experimental alloys during thermal exposure, several specimens $10 \mathrm{~mm} \times 15 \mathrm{~mm} \times 2 \mathrm{~mm}$ in size, were cut from the plate at T8 temper. These specimens were then subjected to different over-aging heat treatments within the temperature range of $70{ }^{\circ} \mathrm{C}-320^{\circ} \mathrm{C}$, the soaking time ranging from $250 \mathrm{~h}$ up to $1300 \mathrm{~h}$. The microhardness was measured by HV-1000 (Shanghai Yanrun Light Machinery Technology Co., Ltd., Shanghai, China), with a loading force of $0.2 \mathrm{~kg}$ and a loading time of $20 \mathrm{~s}$. Tensile tests of specimens were performed at the temperatures from $25^{\circ} \mathrm{C}$ to $300^{\circ} \mathrm{C}$, an Instron machine (INSTRON, Boston, MA, USA) equipped with incubator was used. The specimens were taken in the longitudinal direction from alloy plates at T8 temper. 
The microstructure of the precipitate was examined by transmission electron microscopy (JEOL-2100F, JEOL Corp., Tokyo, Japan) at an accelerating voltage of $200 \mathrm{kV}$. TEM foils were prepared by the twin-jet polishing technique using a solution of $25 \%$ nitric acid and $75 \%$ methanol at $-30{ }^{\circ} \mathrm{C}$, 70-80 mA, and $15 \mathrm{~V}$. Grain structure of the specimens was determined after being anodized with Barker's reagent $\left(1.8 \% \mathrm{HBF}_{4}\right.$ solution with a voltage of $20-30 \mathrm{~V}$ and a current of $0.5-1.5 \mathrm{~mA}$, Quanzhou, China) and viewed with polarized light on optical microscope (ZEISS, Oberkochen, Germany). The evaluation of the fracture features of the high-temperature tensile specimen was performed with an FEI-Nova Nano SEM 450 scanning electron microscope (FEI Company, Hillsboro, OR, USA).

To verify the inhibiting effect of small Ce addition on $\mathrm{T} 1$ phase coarsening, a diffusion couple was designed. Firstly, a pure aluminum plate was sandwiched between a Ce-free alloy and a Ce-containing alloy (The oxide layer at the joint of alloy sheet was polished clean by water grinding sand). Then it was drilled and fixed with copper wire. After short-time preheating, it was tightly welded by rolling and then annealed at $520^{\circ} \mathrm{C}$ for $6 \mathrm{~h}$. The formation of a new oxide layer was prevented by inert gas protection during annealing and rolling. The cross section of the specimen was polished in accordance with metallographic standard and then observed by SEM.

\section{Results and Discussion}

The initial microstructures of Ce-containing and Ce-free alloys at $\mathrm{T} 8$ temper were characterized both by TEM and three-dimensional OM investigations, as shown in Figure 1. Figure 1a shows that the main precipitate in two alloys is uniformly distributed T1 phase at T8 temper. A small pre-stretching before aging induces dislocation network within the matrix, which acts as heterogeneous nucleation sites for the T1 phase and greatly promotes $\mathrm{T} 1$ phase precipitation [28].
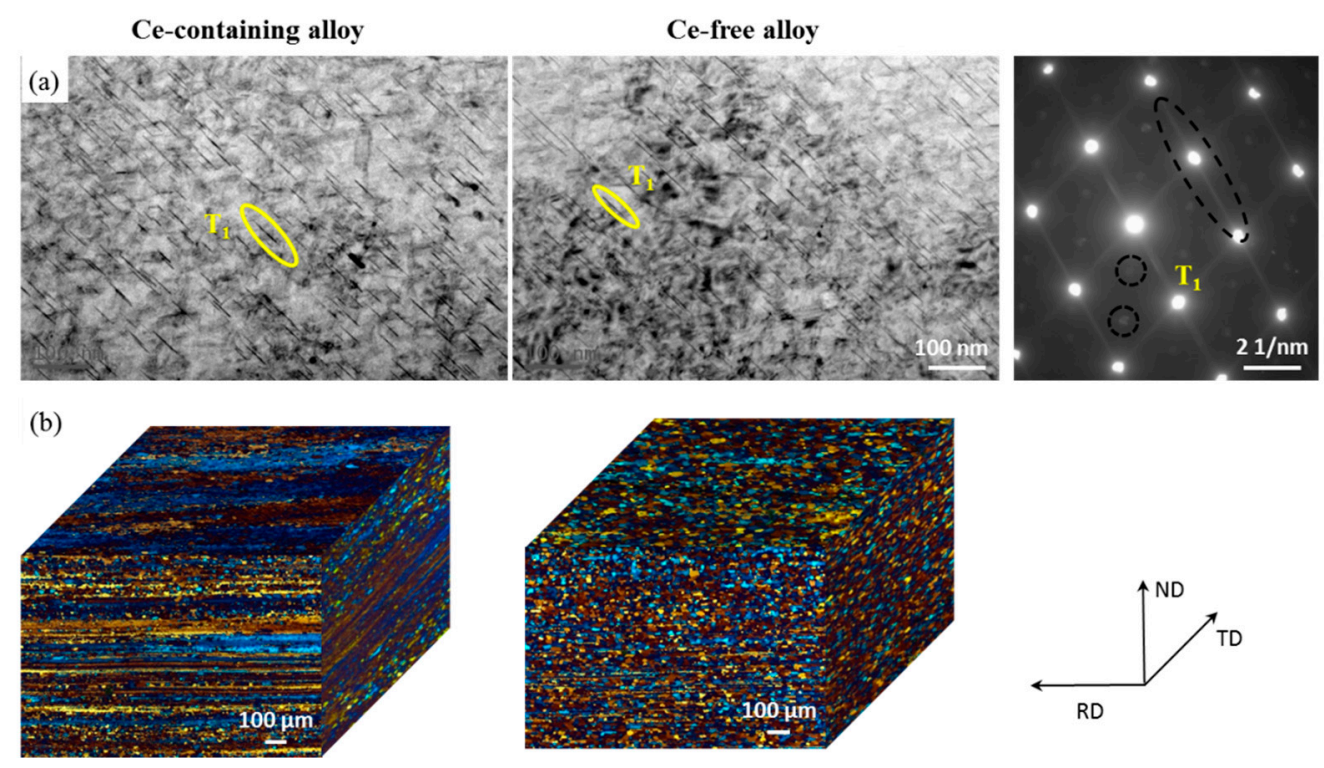

Figure 1. Microstructures comparison of Ce-containing and Ce-free alloys at T8 temper: (a) TEM image of T1 phase; (b) three direction optical micrographs of grain structure.

Although the distribution characteristics of $\mathrm{T} 1$ phase are not affected by Ce addition, many fiber-like unrecrystallized microstructures are found distributed along the rolling direction in the Ce-containing alloy while the recrystallized grains are primarily observed in Ce-free alloy (Figure 1b), Clearly $\mathrm{Ce}$ addition effectively improves the recrystallization resistance of $\mathrm{Al}-\mathrm{Cu}-\mathrm{Li}$ alloys during solid solution treatment [1]. Therefore, the initial microhardness of Ce-containing alloy $\left(189 \mathrm{HV}_{0.2}\right)$ is greater than that of Ce-free alloy $\left(177 \mathrm{HV}_{0.2}\right)$. Moreover, this is mainly attributed to the grain size difference between them. 
The thermal stability curves of Ce-containing and Ce-free alloys at T8 temper which are characterized by microhardness and obtained in the range $70-320^{\circ} \mathrm{C}$ for soaking time from $250 \mathrm{~h}$ to $1300 \mathrm{~h}$, are reported in Figure 2. The microhardness of Ce-containing alloy is found to be much higher than that of Ce-free alloy within the temperature range from $170{ }^{\circ} \mathrm{C}$ to $270{ }^{\circ} \mathrm{C}$. At temperatures no higher than $120^{\circ} \mathrm{C}$, good thermal stability is observed in both alloys. As the temperature further increases to $320^{\circ} \mathrm{C}$, the hardness values of the two alloys become similar again. The thermal stability of the $\mathrm{Al}-\mathrm{Cu}-\mathrm{Li}$ alloy is substantially improved by small $\mathrm{Ce}$ addition during thermal exposure at medium-high-temperature stage $\left(170{ }^{\circ} \mathrm{C}\right.$ to $\left.270{ }^{\circ} \mathrm{C}\right)$.

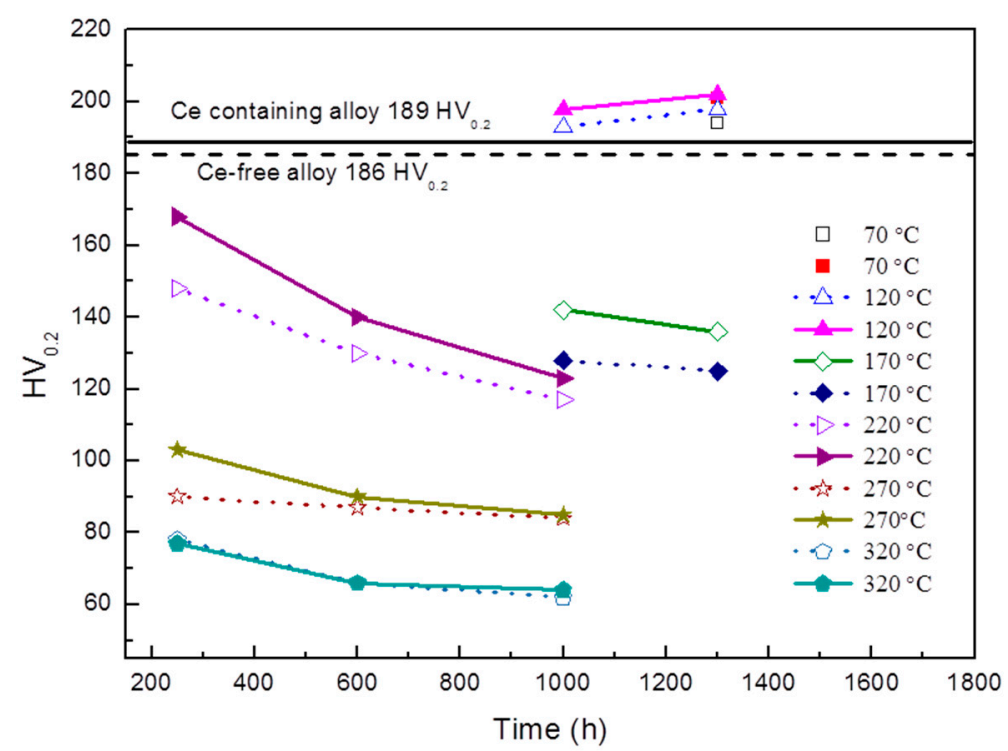

Figure 2. Thermal stability curves of Ce-containing and Ce-free alloys during thermal exposure at the temperature range $70-320^{\circ} \mathrm{C}$ for soaking time from $250 \mathrm{~h}$ to $1300 \mathrm{~h}$.

The precipitate phase characteristics of Ce-containing and Ce-free alloys after thermal exposure at $170{ }^{\circ} \mathrm{C}$ for $1000 \mathrm{~h}$ and $220^{\circ} \mathrm{C}$ for $250 \mathrm{~h}$ were investigated respectively by using TEM, as shown in Figure 3. The thickness of the precipitates in Ce-containing alloy is $25.40 \pm 6.52 \mathrm{~nm}$ (average \pm standard deviation), which is much lower than that in Ce-free alloy $\left(31.22 \pm 10 \mathrm{~nm}\right.$ ) after exposure at $170{ }^{\circ} \mathrm{C}$ for $1000 \mathrm{~h}$. Although the diameter (length) of the precipitates in Ce-free alloy $(114.45 \pm 29.70 \mathrm{~nm})$ is slightly more than that in Ce-containing alloy $(106.35 \mathrm{~nm} \pm 28.19 \mathrm{~nm})$, the effect of thickness increment of the precipitates $(22.91 \%)$ is much more potent compared with that of their diameter increment $(7.62 \%)$. After exposure at $220^{\circ} \mathrm{C}$ for $250 \mathrm{~h}$, the thickness of precipitates in Ce-containing alloy becomes $16.85 \pm$ $3.41 \mathrm{~nm}$, which is much lower than that in Ce-free alloy $(27.58 \pm 7.25 \mathrm{~nm})$. Moreover, the diameter of precipitates in Ce-containing alloy turns to $196.11 \pm 55.65 \mathrm{~nm}$, which is much greater than that in Ce-free alloy (113.46 $\pm 35.96 \mathrm{~nm})$. Ce addition is beneficial to slowing down the coarsening rate of the main phase T1 in the Al-Cu-Li alloy. These plate phase T1 precipitate along the $\{111\}_{\alpha}$ and it is non-deformable [29], the "strengthening stress $\tau_{p}$ " produced by these phases can be expressed as [30].

$$
\tau_{p}=0.12 G \frac{b}{(D t)^{1 / 2}}\left[f_{v}^{\frac{1}{2}}+0.70(D / t)^{\frac{1}{2}} f_{v}+0.12(D / t) f_{v}^{\frac{3}{2}}\right] \ln \frac{0.079 D}{r_{0}}
$$

$D$ and $t$ refer to the diameter and thickness of T1 phase respectively. Formula (1) shows that the strengthening stress varies inversely with the thickness and directly with the diameter of the T1 phase. Because Ce addition is beneficial to slowing down the coarsening rate of the $\mathrm{T} 1$ phase in the $\mathrm{Al}-\mathrm{Cu}-\mathrm{Li}$ alloy, the thickness of the precipitates of $\mathrm{T} 1$ in the Ce-containing alloy is much lower than that in Ce-free alloy during thermal exposure at $170{ }^{\circ} \mathrm{C}$ for $1000 \mathrm{~h}$ and $220^{\circ} \mathrm{C}$ for $250 \mathrm{~h}$. Since $\mathrm{Cu}$ is one of the main elements in the $\mathrm{T} 1$ phase, the coarsening rate of the main strengthening phase $\mathrm{T} 1 \mathrm{in}$ the $\mathrm{Al}-\mathrm{Cu}-\mathrm{Li}$ 
alloy can be reduced through inhibiting the diffusion and convergence of the main element Cu on T1 phase during medium-high temperature thermal exposure. To prove this inference, a diffusion couple was designed to evaluate the effect of $\mathrm{Ce}$ addition on the diffusion of $\mathrm{Cu}$ in the Al-Cu-Li alloys, as shown in Figure 4. Two diffusion interfaces were taken as the starting point, and a quantitative EDS (Energy scattering X-ray spectrum) analysis was done along the solid line arrow in every $10 \mu \mathrm{m}$ in Figure 4. The diffusion rate of $\mathrm{Cu}$ atoms from $\mathrm{Ce}$-containing alloy to pure $\mathrm{Al}$ is much lower than that from $\mathrm{Ce}$-free alloy to pure $\mathrm{Al}$, as shown in the mapping of $\mathrm{Cu}$ distribution and $\mathrm{Cu}$ content distribution curve along the solid line arrow. So the reduced diffusion rate of $\mathrm{Cu}$ in the $\mathrm{Al}-\mathrm{Cu}-\mathrm{Li}$ alloy through $\mathrm{Ce}$ addition was confirmed by the diffusion couple experiment.

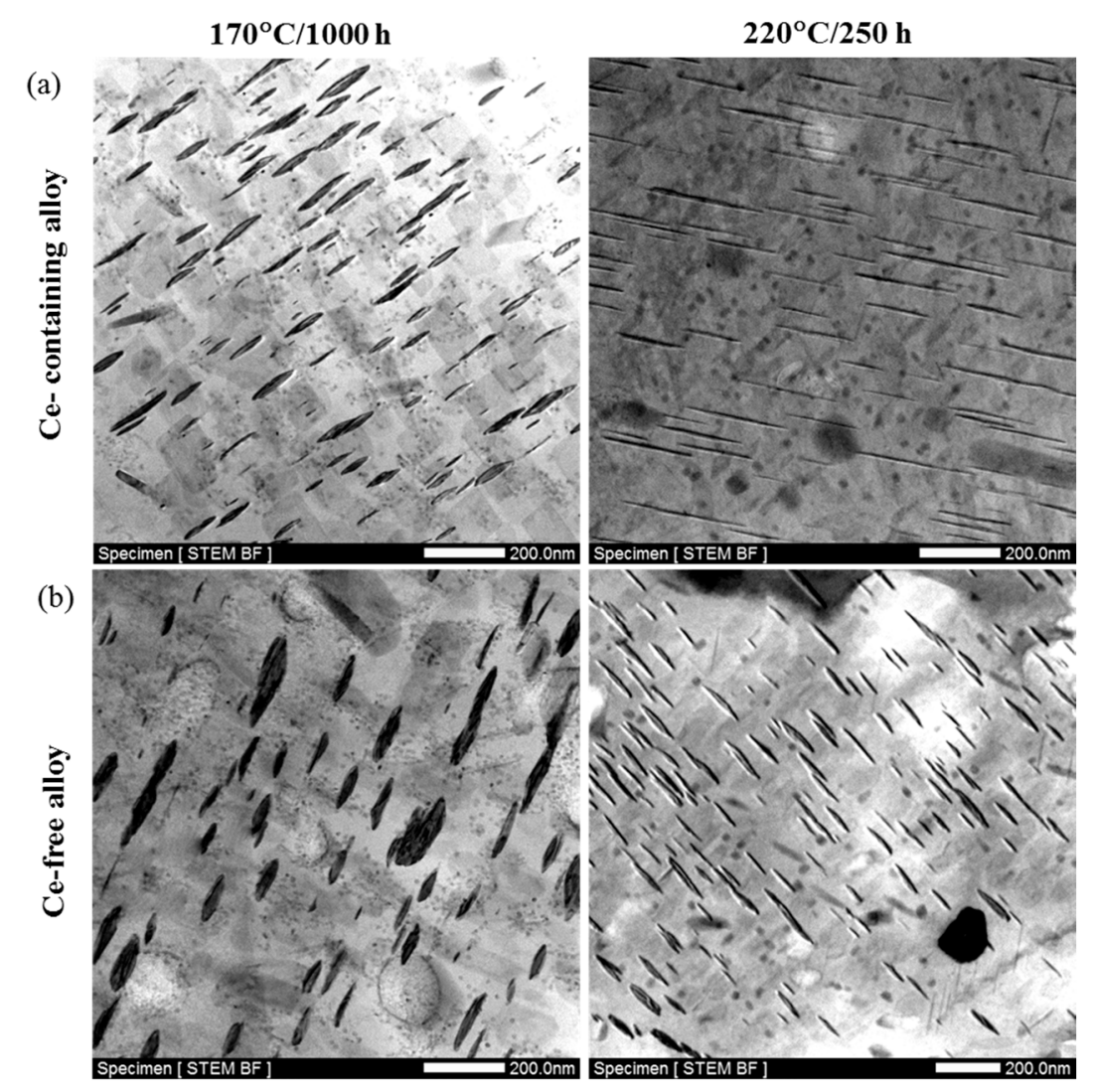

Figure 3. The precipitate phase coarsening characteristics of (a) Ce-containing and (b) Ce-free alloys after exposure at $170{ }^{\circ} \mathrm{C}$ for $1000 \mathrm{~h}$ and $250^{\circ} \mathrm{C}$ for $250 \mathrm{~h}$.

The effect of Ce addition is attributed to the strong interaction energy between rare earth Ce and vacancies in solid solution matrix, which can prevent the migration of dislocation and solute atom [16,17]. Hence small Ce in solid solution can prevent the diffusion of major element $\mathrm{Cu}$ in experimental alloys, and ultimately inhibit the coarsening of strengthening phases $\mathrm{T} 1$ in the $\mathrm{Al}-\mathrm{Cu}-\mathrm{Li}$ alloy. Furthermore, due to the large size mismatch of $\mathrm{Ce}$ and $\mathrm{Al}$ atoms, $\mathrm{Ce}$ tends to segregate at the crystallographic interfaces for relieved lattice strain. The segregation of Ce at the edge interface of precipitates would effectively restrict its lateral growth and inhibit its coarsening. This would likewise decrease the copper diffusion rates as it decreases the tendency for higher diffusive flux between precipitates looking to coarsen. Therefore, the improved thermal stability of the Al-Cu-Li alloy during thermal exposure at the medium-high-temperature stage is attributed to the coarsening inhibition of the main strengthening phases $\mathrm{T} 1 \mathrm{by}$ reducing the diffusion rate of $\mathrm{Cu}$ element and restricting lateral growth through small Ce addition. 


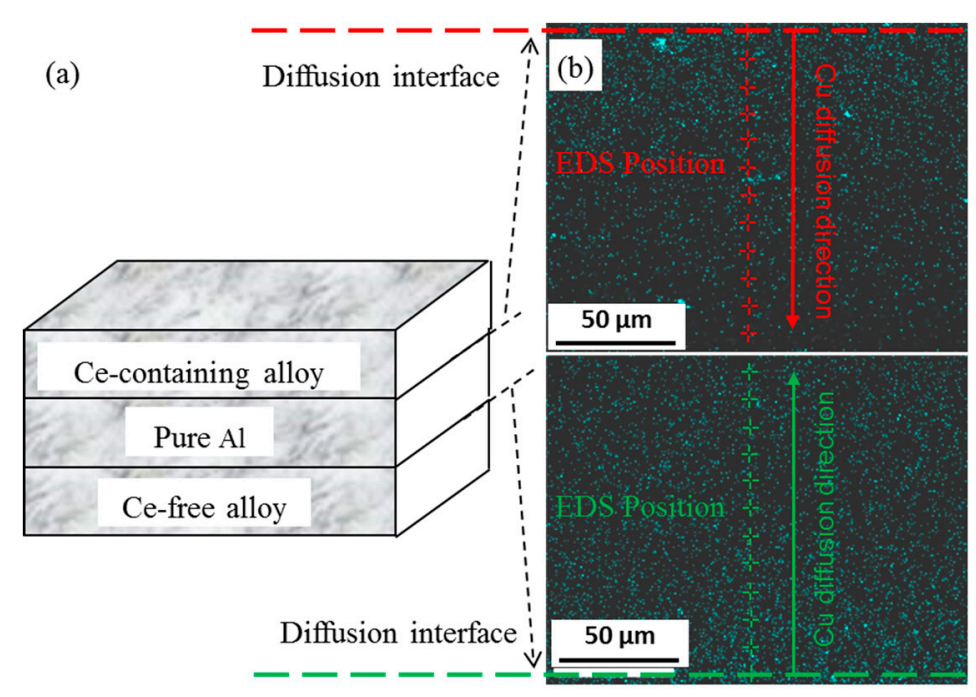

(c)

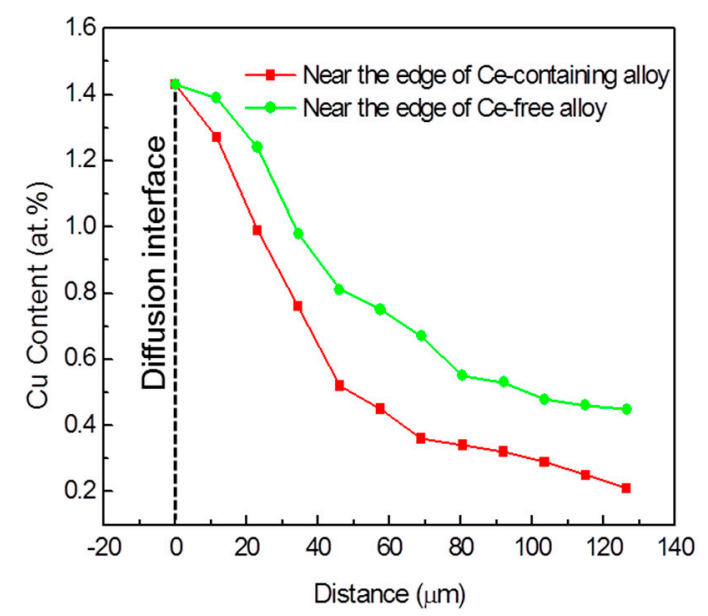

Figure 4. (a) Diagram of diffuse couple model; (b) mapping of $\mathrm{Cu}$ distribution and (c) $\mathrm{Cu}$ content distribution curve along the solid line arrow in pure $\mathrm{Al}$ near the edge of the Ce-containing alloy and the Ce-free alloy respectively.

Figure 5 is the microstructure and element mapping of precipitates in Ce-containing and Ce-free alloys after exposed at $270{ }^{\circ} \mathrm{C}$ for $250 \mathrm{~h}$. Although the main strength phase $\mathrm{T} 1$ has been completely dissolved, a few new particles containing $\mathrm{Al}, \mathrm{Cu}$, and Ce with an average size of about $80 \mathrm{~nm}$ were found dispersed in the matrix. Moreover, a large number of smaller and uniformly distributed particles in the matrix were also observed in Ce-containing alloy, as shown in Figure 5a. In contrast to the case for Ce-containing alloy, some coarse rod-like phases with "fingerprint patterns" can still be seen in Ce-free alloy, which are dissolution marks of the residual phases of severely coarsened T1 phase. Only very few coarse AlCuZr particles with the size of $200 \mathrm{~nm}$, and some small unevenly distributed particles can be seen in Ce-free alloy, as shown in Figure 5b. The hardness difference between the two alloys is about $15 \mathrm{HV}_{0.2}$ (strength value is about $50 \mathrm{MPa}$ ), which is basically due to the contribution of the newly formed $\mathrm{AlCuCe}$ phase in Ce-containing alloy. Since the $\mathrm{AlCuCe}$ particles and those smaller newly observed particles are evenly dispersed in the alloy and remain stable in high temperature, Ce-containing alloy still exhibits better thermal stability than Ce-free alloy after thermal exposure at $270{ }^{\circ} \mathrm{C}$ for $250 \mathrm{~h}$. 

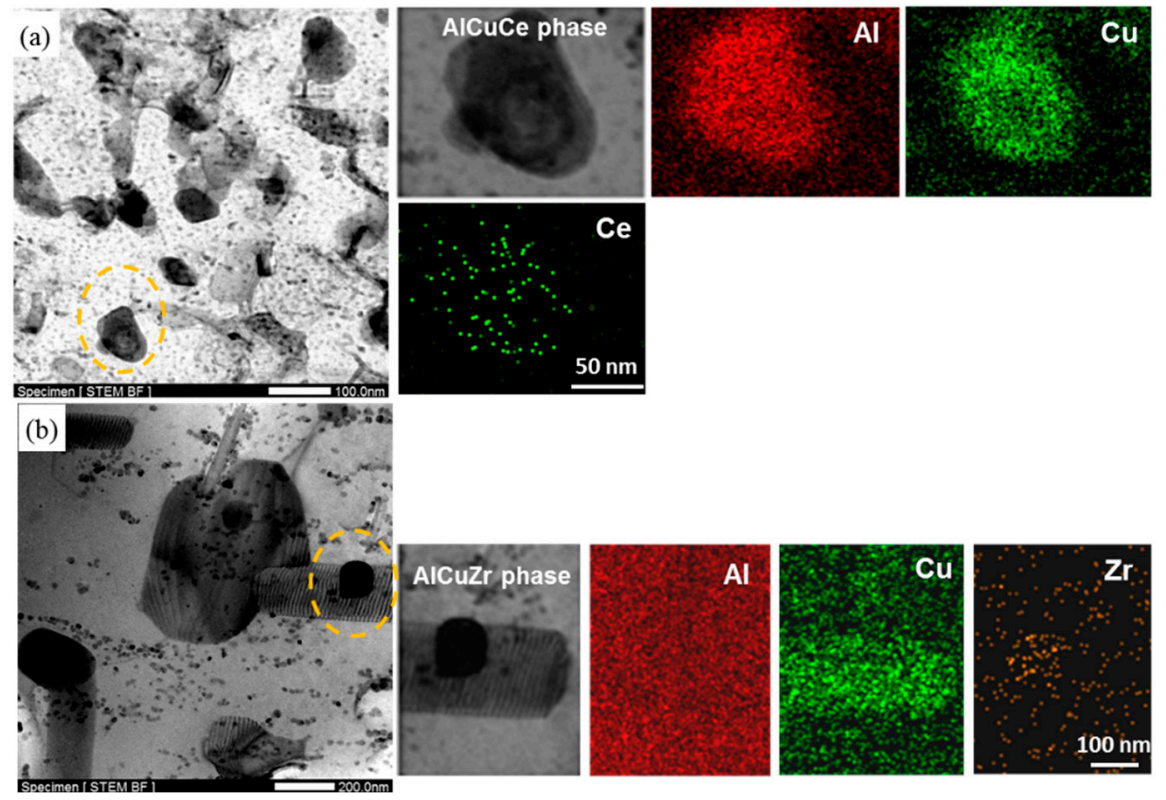

Figure 5. The characteristics and STEM-EDS mapping analysis of precipitates in (a) Ce-containing and (b) Ce-free alloys after exposure at $270{ }^{\circ} \mathrm{C}$ for $250 \mathrm{~h}$.

In addition, the two experimental alloys exhibit excellent thermal stability during exposure at temperatures below $120^{\circ} \mathrm{C}$, as shown in Figure 2. So the microstructures of the alloys after exposure at $120^{\circ} \mathrm{C}$ for $1300 \mathrm{~h}$ were also observed by TEM, as shown in Figure 6 . The stable strengthening phase T1 of the $\mathrm{Al}-\mathrm{Cu}-\mathrm{Li}$ alloy does not coarsen in both experimental alloys and a large number of densely distributed particles appear in the matrix, this is the main reason why the thermal stability of these alloys is maintained during exposure at $120^{\circ} \mathrm{C}$. The relative $\mathrm{Cu}$ content of the newly formed particle is compared semi-quantitatively with that of the matrix and plate phase T1 by STEM-EDS, as shown in Figure 7. The $\mathrm{Cu}$ content of this new particle is higher than that of $\mathrm{T} 1$ phase, thus the particle might be the square-shaped $\mathrm{Al}_{5} \mathrm{Cu}_{6} \mathrm{Li}_{2}$ phase [31]. The $\mathrm{Al}-\mathrm{Cu}-\mathrm{Li}$ alloys exhibit excellent thermal stability during exposure at temperatures below $120^{\circ} \mathrm{C}$ because there is no obvious coarsening of the stable $\mathrm{T} 1$ phase and the fine $\mathrm{Al}_{5} \mathrm{Cu}_{6} \mathrm{Li}_{2}$ phase is formed at the same time.
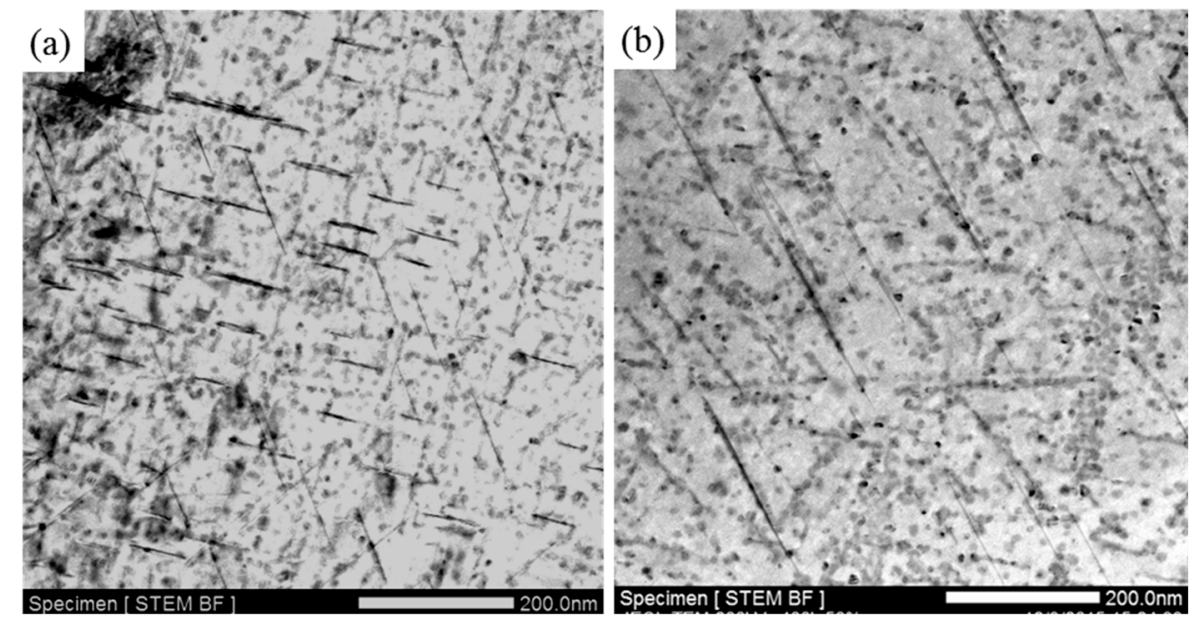

Figure 6. The precipitate characteristics of (a) Ce-containing and (b) Ce-free alloys after exposure at $120^{\circ} \mathrm{C}$ for $1300 \mathrm{~h}$. 

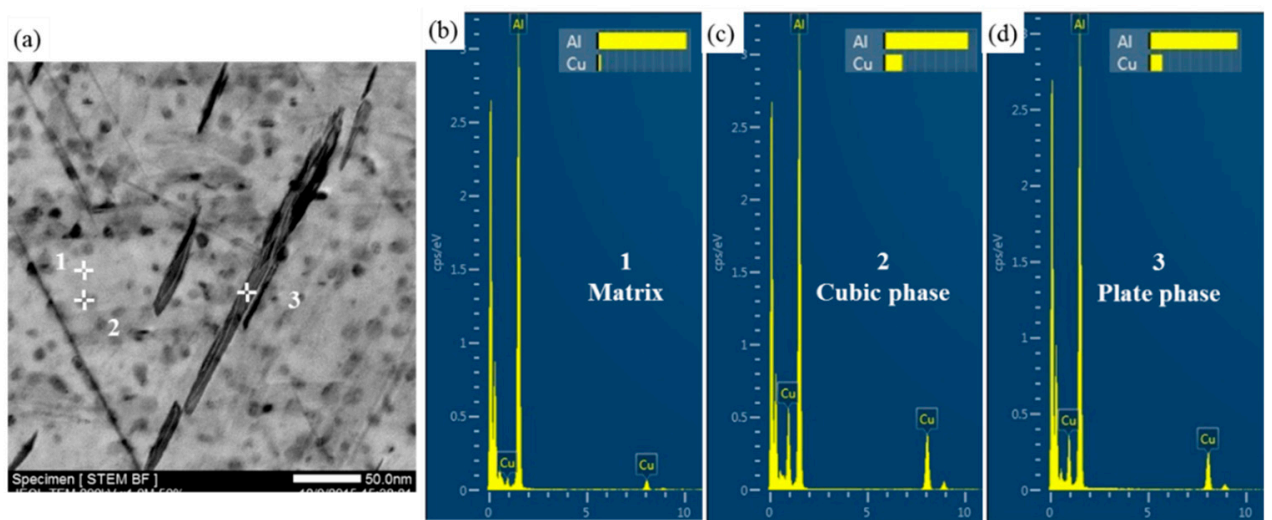

Figure 7. (a) TEM image of the precipitates in Ce-free alloy after exposure at $120{ }^{\circ} \mathrm{C}$ for $1300 \mathrm{~h}$; STEM-EDS analysis of the matrix (b), cubic phase (c), and plate phase (d) as point 1 , point 2 , and point 3 , respectively.

The size and morphology of intermetallics in Ce-containing and Ce-free alloys after solid solution were investigated by SEM and EDS, as shown in Figure 8. The average transverse size of intermetallic particles $\mathrm{AlCuCe}$ in Ce-containing alloy is less than $6 \mu \mathrm{m}$. However, a few coarse intermetallic particles $\mathrm{AlCuZr}$ about $25 \mu \mathrm{m}$ are also observed besides the normal small particles in Ce-free alloy. Obviously, the formation of coarse $\mathrm{AlCuZr}$ intermetallic compounds was interrupted by the strong attraction between $\mathrm{Cu}$ and $\mathrm{Ce}$ atoms in Ce-containing alloy [32], for the electronegative differences between $\mathrm{Ce}$ and $\mathrm{Cu}$ are more than that between $\mathrm{Zr}$ and $\mathrm{Cu}$ [17]. In addition, $\mathrm{Ce}$ and $\mathrm{Zr}$ have the opposite microsegregation patterns similar to that of $\mathrm{Mn}$ and $\mathrm{Zr}$ in $\mathrm{Al}$ alloy during solidification [33], so the Ce and $\mathrm{Zr}$ atoms combine with $\mathrm{Cu}$ respectively and transport in the opposite direction during solidification, thereby avoiding the formation of coarse $\mathrm{AlCuZr}$ phase. Moreover, the Ce addition would affect and refine the formation of interdendritic compounds due to supersaturated Ce atoms being expelled from the solidified grains and accumulated at the front of the interface between solid and liquid during solidification [16]. Hence, the formation and refinement of the AlCuCe phases are promoted through Ce addition.

(a)
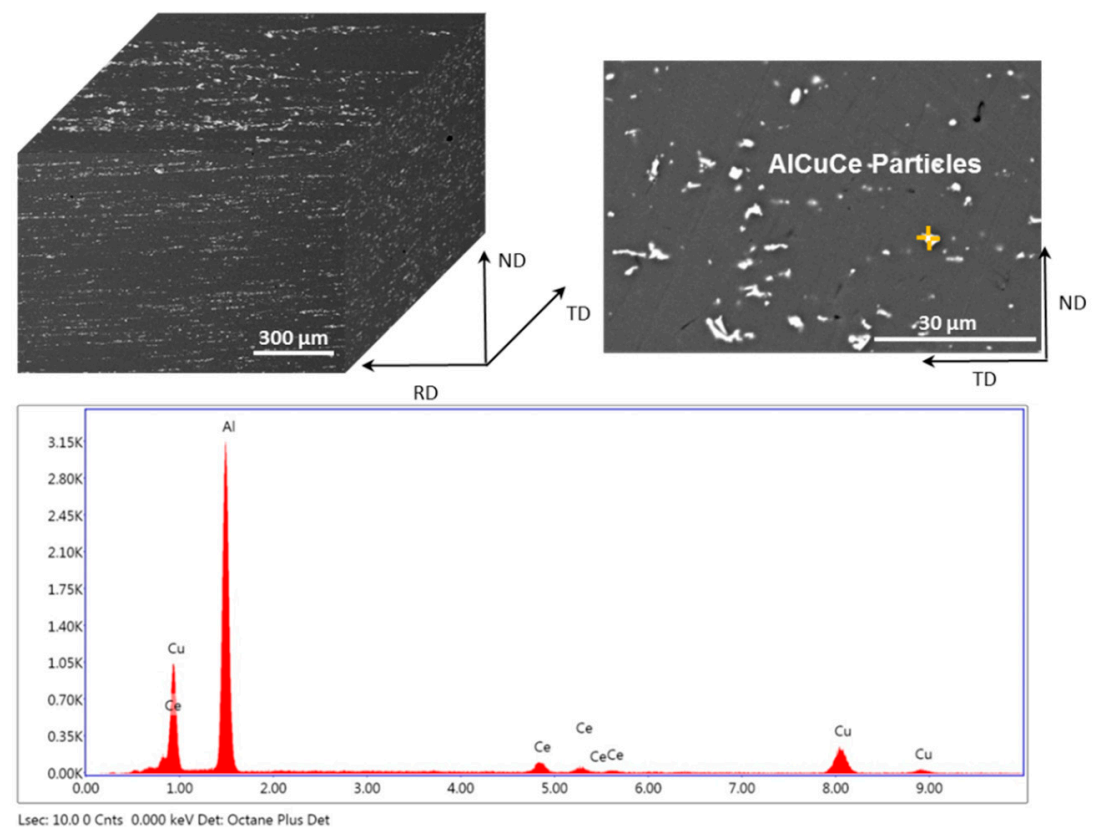

Figure 8. Cont. 
(b)
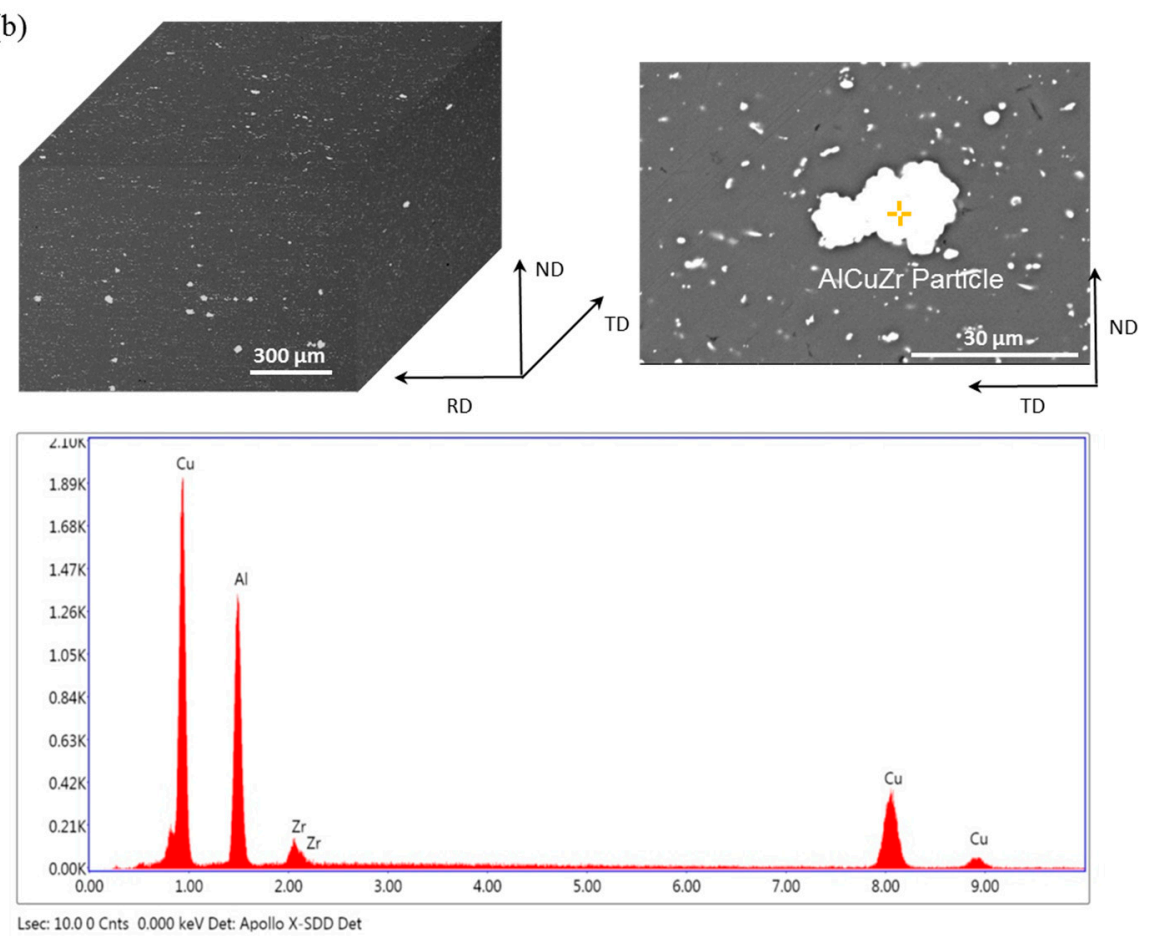

Figure 8. The characteristics and EDS analysis of the intermetallic in (a) Ce-containing and (b) Ce-free alloys after solid solution at $520^{\circ} \mathrm{C}$ for $1 \mathrm{~h}$.

To study the effects of the refined Ce-containing intermetallic on high-temperature tensile properties of the experimental alloys at $\mathrm{T} 8$ temper, the tensile test curves of Ce-containing and Ce-free alloys were investigated at $25^{\circ} \mathrm{C}, 100^{\circ} \mathrm{C}, 175^{\circ} \mathrm{C}, 250^{\circ} \mathrm{C}$, and $325^{\circ} \mathrm{C}$, respectively, as shown in Figure 9 . The strength value of Ce-containing alloy is always higher than that of Ce-free alloy within the entire tensile test temperature range. The yield strength of the Ce-containing alloy is higher than that of Ce-free alloy, by $21.5 \mathrm{MPa}$ at $100^{\circ} \mathrm{C}$, by $27.5 \mathrm{MPa}$ at $175^{\circ} \mathrm{C}$, by $13.5 \mathrm{MPa}$ at $250^{\circ} \mathrm{C}$, and by $4.5 \mathrm{MPa}$ at $325^{\circ} \mathrm{C}$. As the temperature increases, the strength difference between the two alloys decreases, whereas the elongation of Ce-containing alloy increased greatly from $7.5 \%$ to $17.5 \%$ at the testing temperature range between room temperature and $325^{\circ} \mathrm{C}$, while that of Ce-free alloy only increased from $7 \%$ to $13 \%$. Ce addition effectively enhances the high-temperature ductility of the Al-Cu-Li alloy, and the strength of this alloy is properly maintained to a certain extent at the same time.

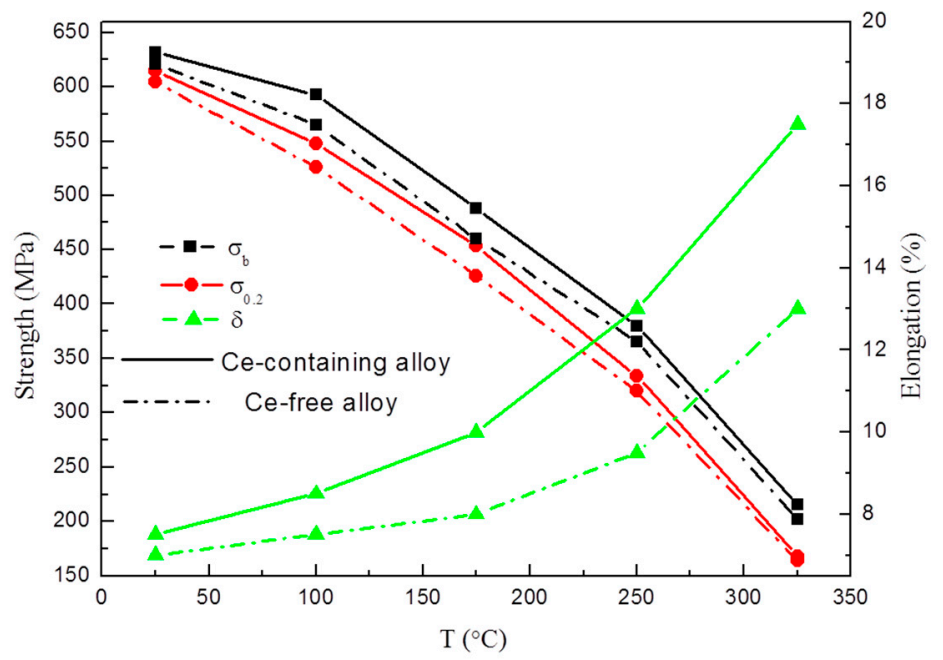

Figure 9. High-temperature tensile curves of Ce-containing and Ce-free alloys at T8 temper. 
To understand the effects of the refined $\mathrm{Cu}$-containing intermetallic particles on the fracture mode of Ce-containing and Ce-free alloys after high temperature tensile, the fracture morphologies of the alloys were investigated comparatively by secondary electron (SE) image and backscatter electron (BSE) image, as shown in Figures 10 and 11. The cleavage facets, which indicate a brittle fracture, are dominant in Ce-free alloy, while only a few facets are seen in Ce-containing alloy at the lower tensile test temperature. Moreover, the fine AlCuCe particles are located in an area with obvious plastic fracture characteristics. As the temperature reaches $250{ }^{\circ} \mathrm{C}$, a large number of dimples are observed in Ce-containing alloy. The dimples in the zone with densely distributed small $\mathrm{AlCuCe}$ particles decrease in size and increase in quantity, which is consistent with the obvious increase of the number of dimples in tensile fracture surface of A357 alloy by addition of rare earth element [34]. As the temperature rises to $325^{\circ} \mathrm{C}$, the dimples further increase in size and are distributed more uniformly. The AlCuCe particles become finer and more dispersive because the fine AlCuCe particles are gradually crushed due to the further softening of the alloy matrix at higher temperature $[1,35]$. Compared with Ce-containing alloy, the coarse $\mathrm{AlCuZr}$ particles are prone to brittle fracture and thus would not contribute to the plastic deformation of the alloy at the whole high-temperature tensile test. Therefore, the small high-temperature stable AlCuCe phase in the Ce-containing alloy is beneficial to the improvement of the ductility of the Al-Cu-Li alloy in high-temperature tensile test.

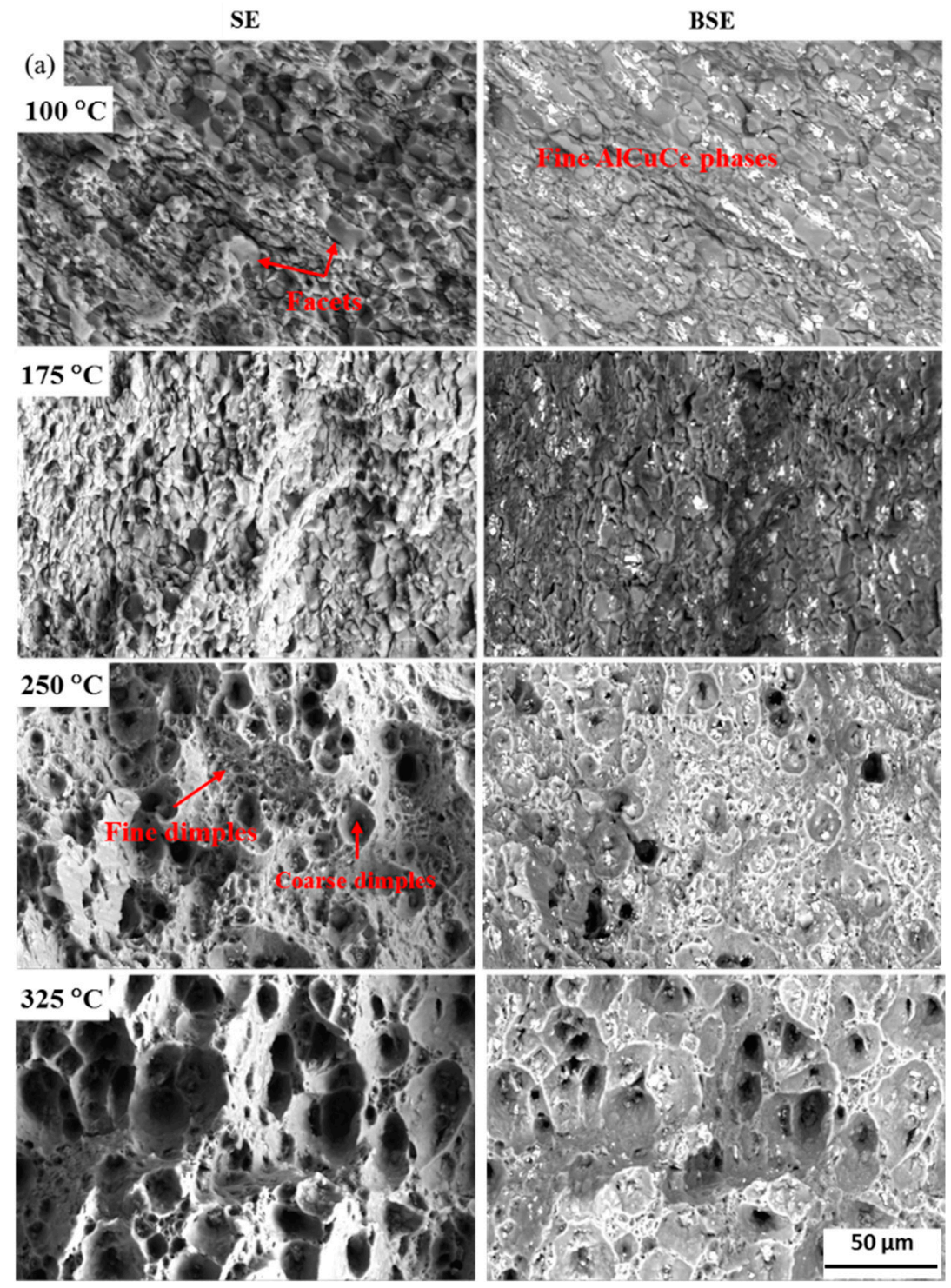

Figure 10. Cont. 
SE
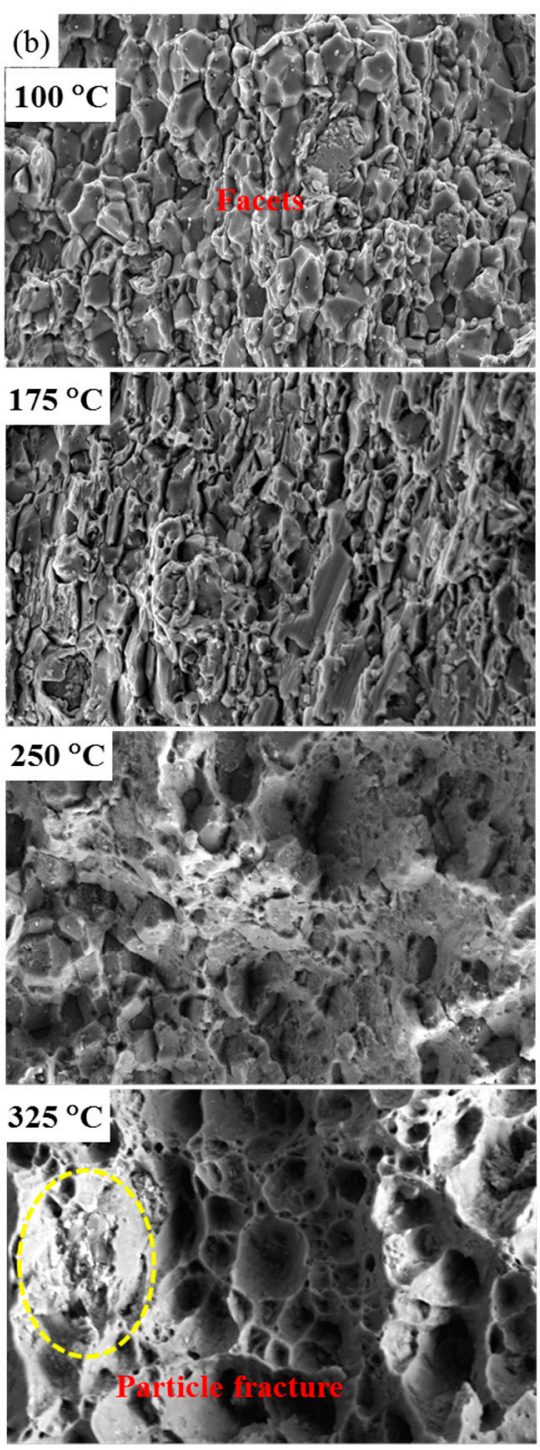

BSE
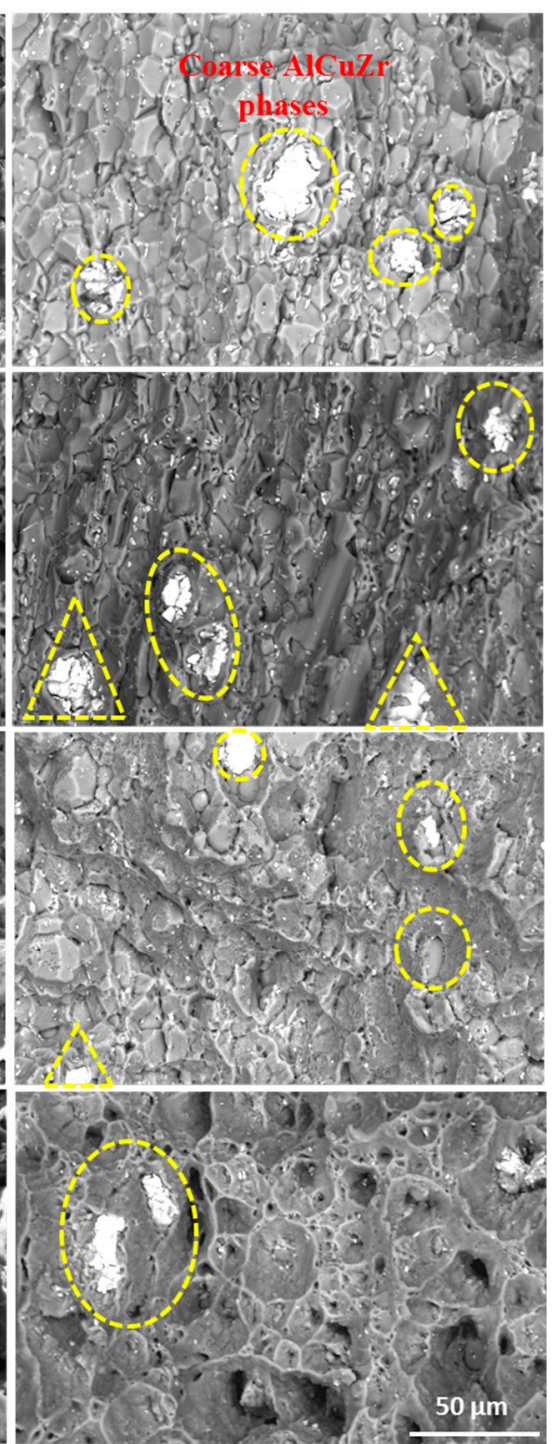

Figure 10. Fracture morphology of (a) Ce-containing and (b) Ce-free alloys after high-temperature tensile at $100{ }^{\circ} \mathrm{C}, 175^{\circ} \mathrm{C}, 250{ }^{\circ} \mathrm{C}$, and $325^{\circ} \mathrm{C}$.

In general, the deformation resistance of metals decreases with temperature. As the temperature increases, the cross-slip and climb of dislocations become easier and the bonding force between atoms is further weakened, which lead to the thermal activation of alloy increase [36]. A large number of studies [37-40] on the deformation behavior of aluminum alloys at elevated temperatures indicated that intermetallic phases with high-temperature stability have a strong pining effect on grain boundaries and sub-grain boundaries, which can compensate for the grain boundary weakening at high temperatures. A large number of fine rare earth intermetallic phases with high temperature stability lead to improved high temperature tensile properties of the $\mathrm{Al}$ alloy, e.g., the tensile strength of 2519 alloy with $0.2 \mathrm{wt} \%$ $\mathrm{Y}$ increased by $30 \%$ at $300{ }^{\circ} \mathrm{C}$, which was attributed to the $\mathrm{Al}_{6} \mathrm{Cu}_{6} \mathrm{Y}$ phase hindering the movement of grain boundary and the deformation of matrix [41]. The $\mathrm{Al}_{11} \mathrm{La}_{3}$ particles were very stable in $\mathrm{Al}-\mathrm{Cu}-\mathrm{La}$ alloy and widely distributed in grain boundaries or dendritic interstices, which effectively hindered dislocation and grain boundary migration during high temperature creep [14]. A large number of small $\mathrm{Al}_{8} \mathrm{Cu}_{4} \mathrm{Ce}$ phases on dispersoid-free grain boundaries have been found in our experimental alloy [1]. These high temperature stable fine particles can produce Zener pinning pressure on $\mathrm{Zr}$ dispersoid-free grain boundaries, and retard its migration during high-temperature annealing. It is expected that the 
small $\mathrm{Al}_{8} \mathrm{Cu}_{4} \mathrm{Ce}$ dispersed phase mainly distributed at grain boundaries can effectively pin dislocations and grain boundaries, which is beneficial to the improvement of high-temperature tensile deformation uniformity and strength of $\mathrm{Al}-\mathrm{Cu}-\mathrm{Li}$ alloy.
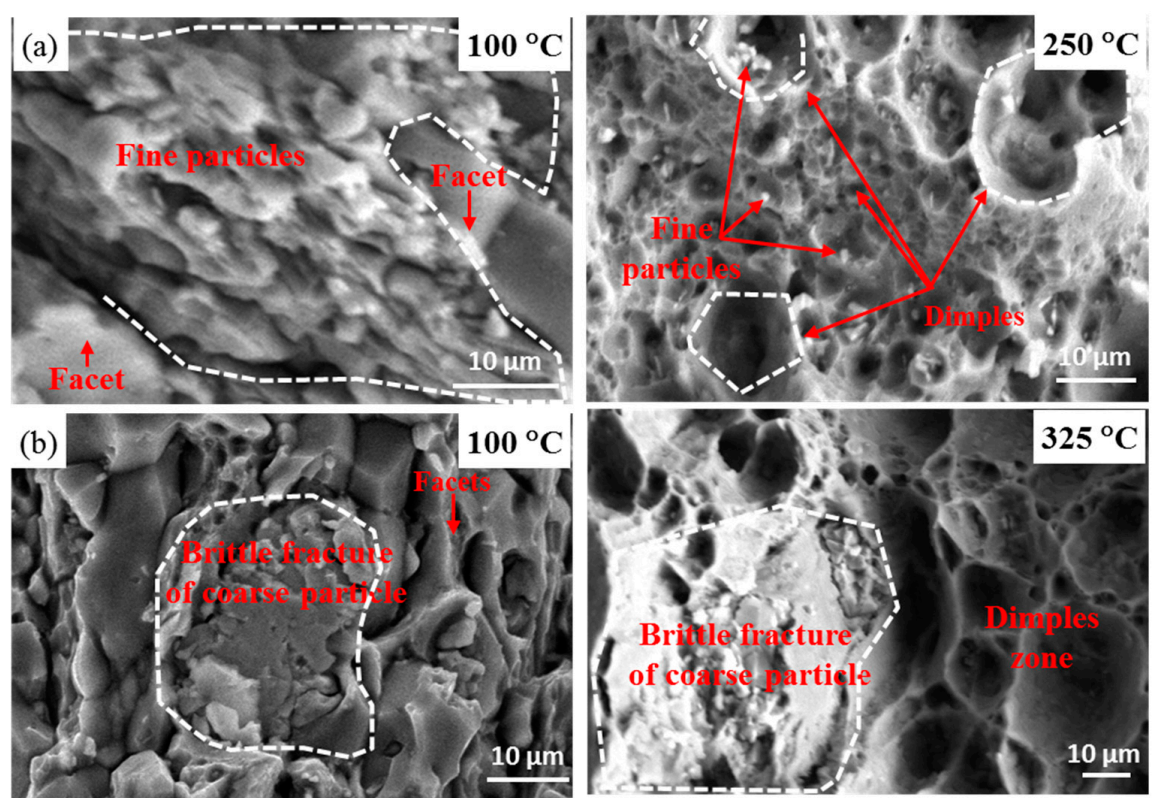

Figure 11. Typical fracture morphologies of (a) Ce-containing and (b) Ce-free alloys after high temperature tensile at $100{ }^{\circ} \mathrm{C}, 250^{\circ} \mathrm{C}$, and $325^{\circ} \mathrm{C}$.

\section{Conclusions}

The inhibition of the main strength phase T1 coarsening through $0.29 \mathrm{wt} \% \mathrm{Ce}$ additions during high-temperature exposure and the effect of element $\mathrm{Ce}$ on the diffusion of $\mathrm{Cu}$ in $\mathrm{Al}-\mathrm{Cu}-\mathrm{Li}$ alloy were investigated. Moreover, the enhancement of deformation uniformity and strength of the Al-Cu-Li alloy due to refined $\mathrm{Al}_{8} \mathrm{Cu}_{4} \mathrm{Ce}$ intermetallic phase in the high-temperature tensile test were also studied in this paper. The following conclusions can be drawn.

(1) The thermal stability of Al-Cu-Li alloy is substantiality improved by Ce addition during thermal exposure at the medium-high-temperature stage $\left(170^{\circ} \mathrm{C}\right.$ to $\left.270{ }^{\circ} \mathrm{C}\right)$. The enhanced thermal stability of Ce-containing alloy can be attributed to the coarsening inhibition of $\mathrm{T} 1$ through impeding the diffusion of $\mathrm{Cu}$. Ce segregates at the interface of the T1 phase can restrict its lateral growth, thereby inhibiting its coarsening.

(2) As the test temperature increases from room temperature to $325^{\circ} \mathrm{C}$, the elongation of Ce-containing alloy increased rapidly from $7.5 \%$ to $17.5 \%$, while that of Ce-free alloy only increased from $7 \%$ to $13 \%$. The high tensile strength of Ce-containing alloy is always higher than that of Ce-free alloy. The high-temperature stable small $\mathrm{Al}_{8} \mathrm{Cu}_{4} \mathrm{Ce}$ phase in Ce-containing alloy can effectively pin dislocations and grain boundaries, which is beneficial to the improvement of the ductility and strength of the alloy in the high-temperature tensile test.

Author Contributions: Conceptualization, X.Y.; data curation, J.S.; methodology, H.D.; project administration, X.Y.; resources, Z.Z. and D.S. Validation, X.Y.; writing—original draft, X.Y.; writing一review and editing, H.D. and X.D.

Funding: This research was funded by (Shandong Provincial Natural Science Foundation, China) grant number (ZR2017PEM005); (A Project of Shandong Province Higher Educational Science and Technology Program) grant numbers (J17KA043, J17KB076, and J18KA053).

Acknowledgments: We thank Caiqiong Li, Junfeng Zhao, Wenwen Liu, and Zhutie Li, from Yantai Nanshan University, for contributing to the experimental work in this manuscript.

Conflicts of Interest: The authors declare no conflict of interest. 


\section{References}

1. Yu, X.X.; Dai, H.; Li, Z.T.; Sun, J.; Zhao, J.F.; Li, C.Q.; Liu, W.W. Improved recrystallization resistance of Al-Cu-Li-Zr alloy through Ce addition. Metals 2018, 8, 1035. [CrossRef]

2. Rodgers, B.I.; Prangnell, P.B. Quantification of the influence of increased pre-stretching on microstructure strength relationships in the Al-Cu-Li alloy AA2195. Acta Mater. 2016, 108, 55-67. [CrossRef]

3. Ma, Y.; Zhou, X.; Thompson, G.E.; Curioni, M.; Skeldon, P.; Zhang, X.; Sun, Z.; Luo, C.; Tang, Z.; Lu, F. Anodic film growth on Al-Li-Cu alloy AA2099-T8. Electrochim. Acta 2012, 80, 148-159. [CrossRef]

4. Rioja, R.J.; Liu, J. The evolution of Al-Li base products for aerospace and space applications. Metall. Mater. Trans. A 2012, 43, 3325-3337. [CrossRef]

5. Polmear, I.J.; Pons, G.; Barbaux, Y.; Octor, H.; Sanchez, C.; Morton, A.J.; Borbidge, W.E.; Rogers, S. After concorde: Evaluation of creep resistant Al-Cu-Mg-Ag alloys. J. Mater. Sci. Technol. 2013, 15, 861-868. [CrossRef]

6. Ortiz, D.; Brown, J.; Abdelshehid, M.; DeLeon, P.; Dalton, R.; Mendez, L.; Soltero, J.; Pereira, M.; Hahn, M.; Lee, E.; et al. The effects of prolonged thermal exposure on the mechanical properties and fracture toughness of C458 aluminum-lithium alloy. Eng. Fail. Anal. 2006, 13, 170-180. [CrossRef]

7. Jabra, J.; Romios, M.; Lai, J.; Lee, E.; Setiawan, M.; Lee, E.W.; Witters, J.; Abourialy, N.; Ogren, J.R.; Clark, R.; et al. The effect of thermal exposure on the mechanical properties of 2099-T6 die forgings, 2099-T83 extrusions, 7075-T7651 plate, 7085-T7452 die forgings, 7085-T7651 plate, and 2397-T87 plate aluminum alloys. J. Mater. Eng. Perform. 2006, 15, 601-607. [CrossRef]

8. Deschamps, A.; Garcia, M.; Chevy, J.; Davo, B.; De Geuser, F. Influence of Mg and Li content on the microstructure evolution of Al-Cu-Li alloys during long-term ageing. Acta Mater. 2017, 122, 32-46. [CrossRef]

9. Balducci, E.; Ceschini, L.; Messieri, S.; Wenner, S.; Holmestad, R. Thermal stability of the lightweight 2099 Al-Cu-Li alloy: Tensile tests and microstructural investigations after overaging. Mater. Des. 2017, 119, 54-64. [CrossRef]

10. Decreus, B.; Deschamps, A.; De Geuser, F.; Donnadieu, P.; Sigli, C.; Weyland, M. The influence of Cu/Li ratio on precipitation in Al-Cu-Li-x alloys. Acta Mater. 2013, 61, 2207-2218. [CrossRef]

11. Dorin, T.; Deschamps, A.; De Geuser, F.; Sigli, C. Quantification and modelling of the microstructure/strength relationship by tailoring the morphological parameters of the T1 phase in an Al-Cu-Li alloy. Acta Mater. 2014, 75, 134-146. [CrossRef]

12. Chen, Z.; Zheng, Z. Microstructural evolution and ageing behavior of the low $\mathrm{Cu}: \mathrm{Mg}$ ratio Al-Cu-Mg Alloys containing Scandium and Lithium. Scr. Mater. 2004, 50, 1067-1071. [CrossRef]

13. Wang, J.; Yi, D.; Lu, B.; Liu, S.; Cao, Y. Effect of yttrium on microstructure and properties of 2618 Aluminum alloy. J. Chin. Rare Earth Soc. 2002, 20, 150-153.

14. Yao, D.; Zhao, W.; Zhao, H.; Qiu, F.; Jiang, Q. High creep resistance behavior of the casting Al-Cu alloy modified by La. Scr. Mater. 2009, 61, 1153-1155. [CrossRef]

15. Yang, J.; Nie, Z.; Jin, T.; Xu, G.; Fu, J.; Ruan, H.; Zuo, T. Effect of trace rare earth element Er on high pure Al-Zn-Mg alloy. Trans. Nonferrous Met. Soc. China 2003, 13, 1035-1039.

16. Yu, X.X.; Yin, D.F.; Yu, Z.M. Effects of cerium and zirconium microalloying addition on the microstructures and tensile properties of novel Al-Cu-Li alloys. Rare Met. Mater. Eng. 2016, 45, 1917-1923.

17. Vončina, M.; Kores, S.; Mrvar, P.; Medved, J. Effect of Ce on solidification and mechanical properties of A360 alloy. J. Alloys Compd. 2011, 509, 7349-7355. [CrossRef]

18. Meng, L.; Zhang, B. Effect of Ce modification on Cu diffusion coefficient in diffusion system of alloy 2090-Al. Acta Metall. Sin.-Engl. 1993, 29, 57-61.

19. Cabibbo, M.; Evangelista, E.; Vedani, M. Influence of severe plastic deformations on secondary phase precipitation in a $6082 \mathrm{Al}-\mathrm{Mg}-\mathrm{Si}$ alloy. Metall. Mat. Trans. A 2005, 36, 1353-1364. [CrossRef]

20. Chen, X.; Zheng, Z.; Li, S.; Wei, X.; Chen, Z. Trace element effects on microstructure and mechanical properties in Al-Cu-Li alloy after thermal exposure. Rare Met. Mater. Eng. 2007, 36, 1024-1028.

21. Chaubey, A.K.; Mohapatra, S.; Jayasankar, K.; Pradhan, S.K.; Satpati, B.; Sahay, S.S.; Mishra, B.K.; Mukherjee, P.S. Effect of cerium addition on microstructure and mechanical properties of $\mathrm{Al}-\mathrm{Zn}-\mathrm{Mg}-\mathrm{Cu}$ alloy. Trans. Indian Inst. Met. 2009, 62, 539-543. [CrossRef] 
22. Lai, J.P.; Jiang, R.P.; Liu, H.S.; Dun, X.L.; Li, Y.F.; Li, X.Q. Influence of cerium on microstructures and mechanical properties of Al-Zn-Mg-Cu alloys. J. Cent. South Univ. Technol. 2012, 19, 869-874. [CrossRef]

23. Yu, X.X.; Yin, D.F.; Yu, Z.M.; Zhang, Y.R.; Li, S.F. Solidification behaviour and the effects of cerium on the intermetallic structure of a novel Al-Cu-Li alloy. Rare Met. Mater. Eng. 2016, 45, 1423-1429.

24. Yu, X.X.; Yin, D.F.; Yu, Z.M.; Zhang, Y.R.; Li, S.F. Microstructure evolution of a novel Al-Cu-Li-Ce alloy during homogenization. Rare Met. Mater. Eng. 2016, 45, 1687-1694.

25. Yu, X.X.; Sun, J.; Li, Z.T.; Dai, H.; Fang, H.J.; Zhang, J.F.; Yin, D.F. Solidification behavior and elimination of undissolved $\mathrm{Al}_{2} \mathrm{CuMg}$ phase during homogenization in Ce-modified $\mathrm{Al}-\mathrm{Zn}-\mathrm{Mg}-\mathrm{Cu}$ alloy. Rare Met. 2018. [CrossRef]

26. Gain, A.K.; Fouzder, T.; Chan, Y.C.; Yung, W.K.C. Microstructure, kinetic analysis and hardness of $\mathrm{Sn}-\mathrm{Ag}-\mathrm{Cu}-1 \mathrm{wt} \%$ nano-ZrO 2 composite solder on OSP-Cu pads. J. Alloys Compd. 2011, 509, 3319-3325. [CrossRef]

27. Yu, X.X.; Zhang, Y.R.; Yin, D.F.; Yu, Z.M.; Li, S.F. Characterization of hot deformation behavior of a novel Al-Cu-Li Alloy using processing maps. Acta Metall. Sin. 2015, 28, 817-825. [CrossRef]

28. Gable, B.M.; Zhu, A.W.; Csontos, A.A.; Starke, E.A., Jr. The role of plastic deformation on the competitive microstructural evolution and mechanical properties of a novel Al-Li-Cu-X alloy. J. Light Met. 2001, 1, 1-14. [CrossRef]

29. Tsivoulas, D.; Robson, J.D.; Sigli, C.; Prangnell, P.B. Interactions between zirconium and manganese dispersoid-forming elements on their combined addition in Al-Cu-Li alloys. Acta Mater. 2012, 60, 5245-5259. [CrossRef]

30. Khan, I.N.; Starink, M.J.; Yan, J.L. A model for precipitation kinetics and strengthening in Al-Cu-Mg alloys. Mater. Sci. Eng. A 2008, 472, 66-74. [CrossRef]

31. Hirosawa, S.; Sato, T.; Kamio, A.; Flower, H.M. Classification of the role of microalloying elements in phase decomposition of Al based alloys. Acta Mater. 2014, 48, 1797-1806. [CrossRef]

32. Pérez-Bustamante, R.; Reyna-Cruz, A.; Acosta-Peña, D.C.; Santillán-Rodríguez, C.R.; Matutes-Aquino, J.A.; Pérez-Bustamante, F.; Maldonado-Orozco, M.C.; Aguilar-Santillán, J.; Martínez-Sánchez, R. Effect of cerium/lanthanum addition on microstructure and mechanical properties of Al7075 alloy via mechanical alloying and sintering. J. Rare Earth. 2016, 34, 420-427. [CrossRef]

33. Tsivoulas, D.; Robson, J.D. Heterogeneous $\mathrm{Zr}$ solute segregation and $\mathrm{Al}_{3} \mathrm{Zr}$ dispersoid distributions in Al-Cu-Li alloys. Acta Mater. 2015, 93, 73-86. [CrossRef]

34. Jiang, W.; Fan, Z.; Dai, Y.; Li, C. Effects of rare earth elements addition on microstructures, tensile properties and fractography of A357 alloy. Mater. Sci. Eng. A 2014, 597, 237-244. [CrossRef]

35. Govindaraju, H.K.; Jayaraj, T.; Sadanandarao, P.R. Evaluation of mechanical properties of as-cast Al-Zn-Ce alloy. Mater. Des. 2010, 31, S24-S29. [CrossRef]

36. Hernandez-Sandoval, J.; Garza-Elizondo, G.H.; Samuel, A.M.; Valtiierra, S.; Samuel, F.H. The ambient and high temperature deformation behavior of Al-Si-Cu-Mg alloy with minor Ti, Zr, Ni additions. Mater. Des. 2014, 58, 89-101. [CrossRef]

37. Cavaliere, P.; Marco, P.P.D. Friction stir processing of a Zr-modified 2014 aluminium alloy. Mater. Sci. Eng. A 2007, 462, 206-210. [CrossRef]

38. Spigarelli, S.; Cabibbo, M.; Evangelista, E.; Bidulská, J. A study of the hot formability of an Al-Cu-Mg-Zr alloy. J. Mater. Sci. 2003, 38, 81-88. [CrossRef]

39. Emami, A.R.; Begum, S.; Chen, D.L.; Skszek, T.; Niu, X.P.; Zhang, Y. Cyclic deformation behavior of a cast aluminum alloy. Mater. Sci. Eng. A 2009, 516, 31-41. [CrossRef]

40. Ibrahim, M.F.; Samuel, E.; Samuel, A.M.; Al-Ahmari, A.M.A.; Samuel, F.H. Metallurgical parameters controlling the microstructure and hardness of Al-Si-Cu-Mg base alloys. Mater. Des. 2011, 32, 2130-2142. [CrossRef]

41. Banerjee, S.; Robi, P.S.; Srinivasan, A.; Kumar Lakavath, P. Effect of trace additions of Sn on microstructure and mechanical properties of Al-Cu-Mg alloys. Mater. Des. 2010, 31, 4007-4015. [CrossRef]

(C) 2019 by the authors. Licensee MDPI, Basel, Switzerland. This article is an open access article distributed under the terms and conditions of the Creative Commons Attribution (CC BY) license (http://creativecommons.org/licenses/by/4.0/). 